\title{
Major issues in threat analysis and resolving such problems: an addendum to the GAP analysis
}

\author{
Thilina D. Surasinghe \\ School of Agricultural, Forest, and Environmental Sciences, Clemson University, Clemson, SC 29634, USA \\ Email: tsurasi@g.clemson.edu
}

Date of publication (online): 26 April 2012 Date of publication (print): 26 April 2012 ISSN $0974-7907$ (online) | 0974-7893 (print)

Editor: Hari Balasubramanian

Manuscript details:

Ms \# 02833

Received 14 June 2011

Final received 08 February 2012

Finally accepted 20 February 2012

Citation: Surasinghe, T.D. (2012). Major issues in threat analysis and resolving such problems: an addendum to the GAP analysis. Journal of Threatened Taxa 4(4): 2545-2550.

Copyright: (C) Thilina D. Surasinghe 2012 Creative Commons Attribution 3.0 Unported License. JoTT allows unrestricted use of this article in any medium for non-profit purposes, reproduction and distribution by providing adequate credit to the authors and the source of publication

Author Details: THILINA DILAN SURAsinghe has conducted a significant number of research on biodiversity of Sri Lanka and published several peer-reviewed scientific articles in numerous journals. He has served as an junior faculty in several Sri Lankan public universities. Currently, he is reading a $\mathrm{PhD}$, majoring Wildlife Biology. His dissertation work is on diversity and distribution of stream salamanders in the montane temperate areas.

Acknowledgements: I would like to express my gratitude to Dr. Robert Baldwin, Clemson University, SC for providing useful comments and feedback on this paper.
Abstract: Identification of regions that warrant conservation attention is a top priority among global environmental concerns. Conventionally, this objective was achieved via recognizing natural landscapes based on the number of IUCN Red Listed species, percentage of endemism and species diversity. A recent innovation in conservation biology is the use of GIS-based threat analysis models to identify key areas of conservation importance. Compared with GAP Analysis, which only identifies biodiversity-rich unprotected lands, threat analysis serves as a rigorous tool in conservation planning which specifically recognizes threats and habitat suitability to different taxa based on a spatially-explicit analysis. Threat analysis is a highly flexible process which involves building up a model with multiple independent (without autocorrelations) variables that both positively and negatively affect distribution and population persistence of a concerned species. Parameters include rate of land-use change, population density, population growth rate, land management regimes, protection status, habitat suitability and land stewardship. Threat analysis models can be used to understand the current status of a particular species (or a community) and can be used to project future trends about the species under consideration. This publication provides an overview of uses of GIS-based threat analyses in conservation biology and provides insights on the limitations of these models and the directions that should be taken in future.

Keywords: Biodiversity conservation, GAP analysis, GIS, land development, land-use, threat analysis.

\section{GAP ANALYSIS}

GAP analysis is a GIS-based scientific methodology that recognizes the extent to which native biodiversity, including wildlife, flora and ecological processes are delegated in our current protected area network. Similarly, GAP analysis identifies all elements and processes of the native biodiversity that occur outside protected areas (Scott et al. 1991). Biodiversity or natural land cover types that are not sufficiently covered by existing conservation lands are considered "gaps" in the protected area network and hence as "gaps" in conservation efforts (Scott et al. 1993). Based on GAP information, conservation authorities and biodiversity experts can provide recommendations to improve the effectiveness of protected areas (Nicolls 1991). Threat analysis is a paramount tool in conservation than GAP analysis where multiple factors are considered on long term survival of species, particularly against human disturbances such as development and urbanization. Apart from identification of conservation gaps, threat analysis discerns the relationship between different land uses and different species. Hence, it distinguishes habitats and populations that are mostly imperiled by human activities (Theobald 2004). 


\section{THREAT ANALYSIS}

Threat analysis is not as straight forward as GAP analysis. The central issues in threat analysis are: (i) identification of key factors that endanger the focal species, such as human disturbances, habitat loss and fragmentation; (ii) identification of suitability of different land cover types as habitats or dispersal corridors; (iii) differentiation among levels of protection provided by different types protected areas; (iv) identification of instances where threats are not localized but broadcast, such as acid deposition, nonpoint source pollution, UVB radiation and wildlife diseases.

The first step in a threat analysis is to identify human-oriented factors that threaten species in the study area with reference to land use types. Species differ significantly in their responses to disturbances (Dale et al. 2000). For example, conversion of mature forests to home gardens may improve butterfly diversity while reducing forest-specialist vertebrate diversity, and road construction is more likely to fragment populations of mammals and herpetofauna (Lindenmayer et al. 2000) than bird populations. Thus, threats should be recognized taxon-specifically, if not species-specifically. Effects of a particular land use type on biota differ depending on intensity, duration and frequency of the disturbances (Romme et al. 1998). For instance, small-scale lumbering may not be very noxious if rate of exploitation is below rates of regeneration, while commercial logging and silviculture can severely alter natural hydrological regimes, vegetation characteristics and microclimate (Thiollay 1997). Further, rapid urbanization and intensive agriculture cause wetland drainage, drastic changes in the natural land settings and geological alterations, severely endangering the survival of most native species (Kammerbauer \& Ardon 1999).

The precise means of identification of threats is another issue. Although major, extensive land use types are mapped, minor land use types are not depicted. But, minor land uses such as mining and secondary homes can impose serious impacts on biodiversity (Theobald 2004). Water-filled mining pits act as ecological traps and attract aquatic breeders but do not ensure the persistence of the offspring. Besides, mining adversely affect local water quality, soil structure, and vegetation (Kondolf 1997). In addition, secondary homes, despite smaller spatial extent of current occurrence functions as development nodes in future land development (Baldwin et al. 2009). Therefore, certain minor landuses can have a significant impact on biodiversity and natural ecosystems disproportionate to their spatial extent. Further, certain land-use land-cover maps do not differentiate different agricultural practices. Different crops require different agro-chemicals and different land settings. Further, the landscape structure of the cropland is determined by physiognomy of the crop. Therefore, impact of agriculture on biodiversity may vary among different crops and farming strategies (Theobald 2003). In such situations, surveying to record minor land use types and different agricultural practices is recommended. It is essential to consult scientific literature and expert ecologists to determine the relationship between land use types and species responses else certain detrimental land use types may get omitted from the threat analysis.

The next step in a threat analysis is to determine suitability of landscape for long term viability of biodiversity via: (i) assessment of the suitability of habitats to maintain minimum viable populations; and (ii) evaluation of the suitability of corridors for dispersal (Crooks \& Sanjayan 2006). It is imperative to recognize the distinction between suitable habitats and suitable corridors. For a given habitat to be deemed suitable, it should sustain all the necessary biological and physical conditions and resources to support growth, development and reproduction of species (Hirzel 2001). A suitable corridor should serve as the least cost pathway among subpopulations with lowest possible mortality (Ricketts 2001). Habitat connectivity is crucial for population persistence since it maintains gene flow, metapopulation interactions, rescue effect and juvenile dispersal (Crooks \& Sanjayan 2006). Suitability of a given corridor needs to be evaluated based on the regional land use patterns and potential threats. Any situation that obstructs species movements such as subsidized predation, physical barriers that predispose dispersing species to mortality such as roads, dams and lack of temporary refuge need to be recognized as threats impeding dispersion and migration (Fischer et al. (2006). Further, the extent of the preferred native vegetation, favorable hydrological regimes, climate, edaphic conditions, geography and other biological resources are some important factors that dictate habitat suitability (Theobald 2003). 
Initially in threat analysis, habitat with preferable natural ecological conditions for the focal species should be selected. Then, human oriented threats with respect to the land uses should be assessed. The final product should contain ecologically most favorable habitats with least threats for the persistence of species. Although land use categories indicate species vulnerability, they do not adequately reflect degree of vulnerability of each species. Hence, a quantified relationship should be drawn between species responses and land use activities (Theobald 2004).

A recent innovation in assessing habitat suitability is inclusion of socioeconomic factors and development pressure into habitat values (Baldwin \& deMaynadier 2009). Some socioeconomic factors that can be included in the development pressure are: human population density, population change, industrial growth and land conversion rates, and willingness to pay (Theobald 2003). Higher human density leads to higher rates of resource exploitation and higher degrees of disturbances. Human population density around protected areas has been often used as an index of biodiversity degradation (Cincotta \& Engelman 2000). Brashares et al. (2001) showed a high correlation between extinction risk in national parks and human population size around national parks. Land transformation modifies ecosystem processes and affects habitat quality resulting in habitat loss and fragmentation (Sanderson et al. 2002). House and road densities are easily accessible and effective socioeconomic factors to evaluate habitat suitability. Higher house and road densities indicate low habitat suitability. House density is a better parameter than population density since population census is tied to primary residence and undermines the influence of secondary homes and recreational sites.

There is a pragmatic link between the house density and alterations of natural landscapes (Theobald 2003). Depending on the overall house and road densities, a scale can be produced ranging from lowest to highest values. Making predictions based on current land uses provides better insights because it shows potential areas with high threat to biodiversity in future. For example, Baldwin \& deMaynadier (2009) developed a development pressure index by multiplying current population density by growth rates where they found that areas with low densities but high growth rates pose greater threats for biodiversity than high density-low growth rate areas. Making perditions on population growth convokes several problems. The growth of already urbanized area can be relatively constant. But, the population growth rate of recently developed or newly industrialized areas can be exponential and difficult to project. Subsidies provided by the central government for biodiversity conservation and management is gradually decreasing, around the world government funds are mostly spent on direct social and economic development (White \& Lovett 1999). Hence, raising funds for conservation and management of protected areas is becoming a responsibility of the public and the park management where funds will be generated via tourism and grant acquisition from the private sector, which is known as the "willingness to pay" the cost of conservation by the public in order to use natural landscapes for recreational, aesthetic and to preserve essential ecosystem functions (Turpie 2003). Incorporation of a measurement on "willingness to pay", such as contingent valuation as a variable in treat analyses is timely.

The third challenge in a threat analysis is to evaluate the protection provided to the focal species within their overall distribution range. Not all the conservation lands protect species equally. The legislative declaration determines the protection status (Wilson et al. 2006). Wildlife in private lands does not receive any protection. Wilderness governed by the central government such as national parks and those protected under international laws such as Ramsar Wetlands, Man and Biosphere Reserves beget the high conservation attention. Sanctuaries and forests managed for silviculture are subjected to exploitation of which the conservation level is intermediate (Wilson et al. 2006). Therefore, conservation level of different habitats and dispersal corridors should be assessed based on legislations. Here, it is highly recommended that a scoring system is adopted for the purpose if evaluation and prioritization.

Threat analysis can only incorporate local effects of land use. But, there are several broadcast effects that severely affect biodiversity such as diffuse-source pollution, acid rains, UV radiation and diseases, which are not affiliated directly with the local land uses or disturbances. Origin of these threats can either be global or human activities happening physically distant from the concerned areas. These broadcast effects cannot be cartographically represented. 
Besides, GIS data on such threats may be non-existent or scarce and difficult to interpret geo-spatially (Wright \& Schindler 1996). For instance, to assess the effect of acid rains we need to access long-term data on soil $\mathrm{pH}$ in multiple locations in the area of interest immediately after a rainfall. In diffuse-source pollution, for example air-borne agro-chemicals can get deposited in wilderness where the presence can only be verified through examining field samples of soil and water for pesticide residues (Myers 1996). Moreover, field measures on acid rains and pollution are usually transient and highly variable in space and time which prevent them from being mapped. Spatial occurrence and relative prevalence of wildlife diseases for different habitats are difficult to map. Distribution of diseases in a given landscape is a function of species movement and means of transmission of infective agents. Therefore, disease prevalence in a selected area is strictly subjected to dramatic changes over time and space (Daszak \& Cunningham 1999). Further, if focal areas have been surveyed for diseases, some information can be gained through a literature survey. However, to generate accurate disease-prevalence maps, surveys should be very spatially broad and representative. Inclusion of climate change into a threat analysis can be highly problematic. Climate change models such as the global circulation model are derived from global climatic data and projections applied for larger geographic areas (Mitchell et al. 1999). Therefore, the applicability of global climate models to geographically limited spatial extents will not provide accurate predictions. To make educated projections on climate change for a local area, we need to have long-term high resolution climatic information for the area of interest.

Globally, decisions on biodiversity conservation are taken from an economy-driven, cost-benefit perspective (Ninan \& Sathyapalan 2005). Therefore, the cost of conservation actions incurred by land purchases, habitat restoration, species management, wages for the park personnel, and maintenance of roads and trails within the protected area is weighted against the potential benefits including tourism and recreation-based revenues, productive use of protected landscapes for sustainable forestry and game production, and preservation of ecosystem goods and services (Watzold et al. 2010). Therefore, inclusion of efficient cost-benefit assessments on conservation is crucial in threat analyses. Linked with the cost of conservation is the irreplaceability of wilderness. With growing anthropocentric demand for lands and natural resources, the lands available for conservation are declining. Thus, a spatially-explicit assessment of landscape irreplaceability with respect to species endemism, landscape permeability, unique community assemblages, and ecological functions is of foremost importance (Das et al. 2006).

Threat analyses are useful in many currently existing large-scale, global and cross-continental conservation planning concepts such as Key Biodiversity Areas (Eken et al. 2004), biodiversity hotspots (Myers et al. 2000; Mittermeier et al. 2005), major tropical wilderness (Mittermeier et al. 1998), global freshwater ecoregions (Abell et al. 2008) and Global 200 (Olson et al. 2002). For instance, in the process of threat analysis, full or partial inclusion of a Key Biodiversity Area within a focal area can be included into the GIS model as a separate variable with a high priority score. Moreover, threat analyses can be implemented as a tool to identify habitats for site-based conservation requiring the immediate conservation attention within the Global 200 or global freshwater ecoregions.

The final output of the threat analysis should integrate all these considerations. It should recognize the susceptibly of wilderness to development pressures and adverse land use practices, ecological habitat suitability, cost effectiveness, and levels of conservation attention received. Then, areas with highest development pressures and anthropogenic disturbances, least existing conservation attention but highest ecological suitability and irreplaceability where increased conservation actions are cost-effective should beget the highest priority in conservation and management. In this way, limited financial and intellectual resources can be successfully allocated for wilderness that seriously requires them. This is a prime need in biodiversity conservation.

\section{REFERENCE}

Abell, R., M.L. Thieme, C. Revenga, M. Bryer, M. Kottelat, N. Bogutskaya, B. Coad, N. Mandrak, S.C. Balderas \& W. Bussing (2008). Freshwater ecoregions of the world: a new map of biogeographic units for freshwater biodiversity conservation. Bioscience 58: 403-414.

Baldwin, R.F. \& P.G. deMaynadier (2009). Assessing threats 
to pool-breeding amphibian habitat in an urbanizing landscape. Biological Conservation 142: 1628-1638.

Baldwin, R.F., S.C. Trombulak \& E.D. Baldwin (2009). Assessing risk of large-scale habitat conversion in lightly settled landscapes. Landscape and Urban Planning 91: 219-225.

Brashares, J.S., P. Arcese \& M.K. Sam (2001). Human demography and reserve size predict wildlife extinction in West Africa. Proceedings of the Royal Society of London Series B: Biological Sciences 268: 2473-2478.

Cincotta, R.P. \& R. Engelman (2000). Nature's Place: Human Population Density and the Future of Biological Diversity. Population Action International, Washington DC, 87pp.

Crooks, K.R. \& M. Sanjayan (2006). Connectivity Conservation. Cambridge University Press, Cambridge, $732 \mathrm{pp}$.

Dale, V.H., S. Brown \& R.A. Haeuber (2000). Ecological principles and guidelines for managing the use of land: a report from the Ecological Society of America. Ecological Applications 10: 639-670.

Das, A., J. Krishnaswamy, K.S. Bawa, M.C. Kiran, V. Srinivas, N.S. Kumar \& K.U. Karanth (2006). Prioritisation of conservation areas in the Western Ghats, India. Biological Conservation 133: 16-31.

Daszak, P. \& A.A. Cunningham (1999). Extinction by infection. Trends in Ecology and Evolution 14: 279.

Eken, G., L. Bennun, T.M. Brooks, W. Darwall, L.D.C. Fishpool, M. Foster, D. Knox, P. Langhammer, P. Matiku \& E. Radford (2004). Key biodiversity areas as site conservation targets. Bioscience 54: 1110-1118.

Fischer, J., D.B. Lindenmayer \& A.D. Manning (2006). Biodiversity, ecosystem function, and resilience: ten guiding principles for commodity production landscapes. Frontiers in Ecology and the Environment 4: 80-86.

Hirzel, H., V. Helfer \& F. Metral (2001). Assessing habitat suitability models with a virtual species. Ecological Modelling 145: 111-121.

Kammerbauer, J. \& C. Ardon (1999). Land use dynamics and landscape change pattern in a typical watershed in the hillside region of central Honduras. Agriculture, Ecosystems and Environment 75: 931-100.

Kondolf, G.M. (1997). Hungry water: effects of dams and gravel mining on river channels. Environmental Management 21: 533-552.

Lindenmayer, D.B., C.R. Margules \& D. Botkin (2000). Indicators of forest sustainability biodiversity: the selection of forest indicator species. Conservation Biology 14: 941950.

Mitchell, J.F.B., T.C. Johns, M. Eagles, W.J. Ingram \& R.A. Davis (1999). Towards the construction of climate change scenarios. Climate Change 41: 547-581.

Mittermeier, R.A., N. Myers, J.B. Thomsen, G.A.B. da Fonseca \& S. Olivieri (1998). Biodiversity Hotspots and Major Tropical Wilderness Areas: Approaches to Setting Conservation Priorities. Conservation Biology 12: 516520.
Mittermeier, R.A., P.R. Gil, M. Hoffman, J. Pilgrim, T. Brooks, C.G. Mittermeier, J. Lamoreux \& G.A.B. Da Fonseca (2005). Hotspots Revisited: Earth's Biologically Richest and Most Endangered Terrestrial Ecoregions. Cemex, Mexico, 391pp.

Myers, N. (1996). Two key challenges for biodiversity; discontinuities and synergisms. Biodiversity Conservation 5: 1025-1034.

Myers, N., R.A. Mittermeier, C.G. Mittermeier, G.A.B. da Fonseca \& J. Kent (2000). Biodiversity hotspots for conservation priorities. Nature 403: 853-858.

Nicholls, A.O. (1991). Examples of the use of generalized linear models in analysis of survey data for conservation evaluation, pp. 191-201. In: Margules, C.R. \& M.P. Austin (eds.). Nature Conservation: Cost Effective Biological Surveys and Data Analysis. CSIRO, Collingwood, Victoria, Australia, 220pp.

Ninan, K.N. \& J. Sathyapalan (2005). The economics of biodiversity conservation: a study of a coffee growing region in the Western Ghats of India. Ecological Economics 55: 61-72.

Olson, D.M. \& E. Dinerstein (2002). The Global 200: Priority ecoregions for global conservation. Annals of the Missouri Botanical garden 89: 199-224.

Ricketts, T.H. (2001). The matrix matters: effective isolation in fragmented landscapes. American Naturalist 158: 87-99.

Romme, W.H., E.H. Everham, L.E. Frelich, M.A. Moritz \& R.E. Sparks (1998). Are large, infrequent disturbances qualitatively different from small? Ecosystems 1: 524-534.

Sanderson, E.W., M. Jaiteh, M.A. Levy, K.H. Redford, A.V. Wannebo \& G. Woolmer (2002). The human footprint and the last of the wild. Bioscience 52: 891-904.

Scott, J.M., B. Csuti, K. Smith, J.E. Estes \& S. Caicco (1991). Gap analysis of species richness and vegetative cover: an integrated biodiversity conservation strategy, pp. 282-297. In: Kohn, K.A. (ed.). Balancing on the Brink of Extinction. Island Press, Washington, DC, 329pp.

Scott, J.M., F. Davis, F. Csuti, R. Noss, B. Butterfield, C. Groves, H. Anderson, S. Caicco, F. D'Erchia, T.C.J. Edwards, J. Ulliman \& R.G. Wright (1993). Gap analysis: a geographic approach to protection of biological diversity. Wildlife Monographs 57: 5-41.

Theobald, D.M. (2003). Targeting conservation action through assessment of protection and exurban threats. Conservation Biology 17: 1-13.

Theobald, D.M. (2004). Placing exurban land-use change in a human modification framework. Frontiers in Ecology and the Environment 2: 139-144.

Thiollay, J.M. (1997). Disturbance, selective logging and bird diversity: a neotropical forest-study. Biodiversity Conservation 6: 1155-1173.

Turpie, J.K. (2003). The existence value of biodiversity in South Africa: how interest, experience, knowledge, income and perceived level of threat influence local willingness to pay. Ecological Economics 46: 199-216.

Watzold, F., M. Mewes, R. van Apeldoorn, R. Varjopuro, T.J. 
Chmielewski, F. Veeneklaas \& M.L. Kosola (2010). Costeffectiveness of managing Natura 2000 sites: an exploratory study for Finland, Germany, the Netherlands and Poland. Biodiversity and Conservation 19: 2053-2069.

Wilson, K.A., M.F. McBride, M. Bode \& H.P. Possingham (2006). Prioritizing global conservation efforts. Nature 440: 337-340.

White, P. \& J. Lovett (1999). Public preferences and willingness-to-pay for nature conservation in the North York Moors National Park, UK. Journal of Environmental Management 55: 1-13.

Wright, R.F. \& D.W. Schindler (1996). Interaction of acid rain and global changes: Effects on terrestrial and aquatic systems. Water Air Soil Pollution 85: 89-99. 